УДК 615.345:299

\title{
ОПРЕДЕЛЕНИЕ ПОКАЗАТЕЛЕЙ КАЧЕСТВА КАПСУЛИРОВАННОЙ ЛЕКАРСТВЕННОЙ ФОРМЫ С ЭКСТРАКТОМ ТРАВЫ КРАПИВЫ КОНОПЛЕВОЙ СУХИМ
}

\author{
(C) Л.М. Федосеева, В.О. Кирьякова*
}

\author{
Алтайский государственный медицинский университет, пр. Ленина, 40, \\ Барнаул, 656054 (Россия), e-mail: kiryakova_viktorya@mail.ru
}

Проводится комплексное изучение надземной части растений рода Urtica (крапивы двудомной, крапивы коноплевой, крапивы жгучей), произрастающих на территории Алтайского края. Получены сухие экстракты из травы крапивы двудомной, травы крапивы коноплевой, травы крапивы жгучей. При изучении технологических свойств экстракта травы крапивы коноплевой сухого установили высокую отсыреваемость, поэтому возникла необходимость разработать состав капсулированной формы с добавлением вспомогательных веществ.

Проведена стандартизация и оценка фармацевтической доступности капсул с экстрактом травы крапивы коноплевой сухим. Определены показатели качества капсул: описание, подлинность (идентифицированы: хлорогеновая кислота, шафтозид, рутин, робинин, кверцитрин, флавоноид апигениновой структуры). Количественное содержание флавоноидов в пересчете на кверцитрин составило $2,05 \pm 0,04 \%$. Установлена фармацевтическая доступность капсул: распадаемость капсул менее 20 мин, растворение более $70 \%$.

Полученные показатели качества использованы для разработки проекта нормативной документации «Твердые капсулы с экстрактом травы крапивы коноплевой сухим».

Ключевые слова: стандартизация капсул, фармацевтическая доступность, экстракт травы крапивы коноплевой сухой.

\section{Введение}

На кафедре фармации АГМУ на протяжении многих лет проводится комплексное изучение растений рода Крапива. Проведены фармакогностические и технологические исследования крапивы двудомной, коноплевой и жгучей. Получены экстракты сухие, в том числе и из травы крапивы коноплевой с условным названиям «Уртикан» [1].

Преимуществами экстрактов сухих является удобство в применении и транспортировке, возможность точного дозирования, устойчивость при хранении. К недостаткам сухих экстрактов относится их высокая гигроскопичность, вследствие чего утрачивается сыпучесть [2]. Поэтому правильный выбор лекарственной формы для экстрактов сухих - необходимое условие для проявления фармакологической активности биологически активных веществ.

Капсулы являются одной из перспективных лекарственных форм для сухих экстракционных препаратов из растительного сырья, обеспечивающих высокую биологическую доступность действующих веществ и защиту экстракта от влияния факторов внешней среды [3].

В результате доклинических исследований нами установлены диуретическая, противовоспалительная, антиоксидатная активность, а также разовая терапевтическая доза экстракта «Уртикан» - 0,25 г.

Изучались технологические свойства экстракта «Уртикан» (сыпучесть, угол естественного откоса,

Федосеева Людмила Михайловна - профессор кафедры фармации, e-mail: kiryakova_viktorya@mail.ru

Кирьякова Виктория Олеговна - старший научный сотрудник лаборатории биомедицины, доцент кафедры фармации, e-mail: ludmila@agmu.ru насыпная масса, влажность, гигроскопичность, отсыреваемость). В результате исследований установили высокую отсыреваемость экстракта - 15-17\%.

Поэтому возникла необходимость разработать пропись с добавлением вспомогательных ве-

\footnotetext{
* Автор, с которым следует вести переписку.
} 
ществ для улучшения технологических свойств экстракта. Состав прописи: экстракт травы крапивы коноплевой сухой 0,25 г, лактозы 0,15 г, - которые помещали в твердые капсулы.

Цель данной работы - стандартизация капсул «Уртикан» с экстрактом травы крапивы коноплевой сухим.

\section{Экспериментальная часть}

Объектом исследования служили пять серий капсул «Уртикан» массой 0,40 г, содержащие по 0,25 г экстракта травы крапивы коноплевой сухого.

Государственная фармакопея ХІІІ издания (2015 г.) и ОФС «Капсулы» и ОСТ 91500.05.001-00 «Стандарты качества лекарственных средств. Основные положения» регламентируют следующие показатели качества: описание, подлинность, средняя масса капсулы, отклонение массы каждой капсулы, отклонение массы содержимого каждой капсулы, распадаемость, растворение, количественное определение содержания биологически активных веществ [4].

В ходе исследований и проведения стандартизации экстракта травы крапивы коноплевой определен комплекс биологически активных соединений, состоящий из флавоноидов, фенолкарбоновых кислот (шафтозид, робинин, кверцитрин, флавоноид апигениновой структуры, хлорогеновая кислота, галловая кислота) [5]. Поэтому в основу определения подлинности и количественного содержания фенольных соединений в капсулах «Уртикан» использовали методики для стандартизации экстракта травы крапивы коноплевой сухого.

Извлечение фенольных соединений проводили спиртом этиловым 70\%. Дальнейшие исследования проводили на хроматографе Милихром A-02. Неподвижная фаза - хроматографическая колонка ProntoSIL 120-5-C18 AQ размером 2,0 × 75 мм. Подвижная фаза: А - трифторуксусной кислоты раствор $0,01 \%$, Б ацетонитрил $100 \%$. Температура колонки $-35^{\circ} \mathrm{C}$, скорость подачи элюента - 100 мкл/мин, объем пробы 2 мкл, градиентное элюирование - изменение концентрации элюента Б от 5\% до 55\% при расходе 3000 мкл элюента А. Идентификацию соединений осуществляли по временам удерживания, спектральным отношениям и характеру УФ-спектров в сравнении со стандартными образцами флавоноидов и производных фенолкарбоновых кислот [6]. В качестве свидетелей использовали стандартные образцы флавоноидов из группы флавонола (рутин - каталожный номер R5143, кверцитрин - каталожный номер Q4952, шафтозид каталожный номер K0135) и флавона (апигенин - каталожный номер A3145, робинин - каталожный номер L9283), фенолкарбоновая кислота (хлорогеновая кислота - каталожный номер Р9263) приобретенные в компании ООО «Сигма-Алдрич Рус».

Количественное содержание суммы флавоноидов определяли спектрофотометрическим методом, основанным на измерении оптической плотности окрашенных комплексов флавоноидов с солями алюминия [7]. Расчет количественного содержания проводили в пересчете на кверцитрин.

Распадаемость определяли на лабораторном приборе «Качающаяся корзинка». Для проведения испытаний отбирали из каждой серии по шесть капсул с экстрактом сухим, помещали по одной в каждую трубку прибора, который, в свою очередь, опускали в сосуд с водой, нагретой до температуры $37 \pm 2{ }^{\circ} \mathrm{C}$. Забор проб проводили в течение 20 мин.

Оценку качества капсул по показателю «Растворение» проводили с использованием прибора типа «Вращающаяся корзинка». При испытании корзинка вращалась в среде растворения - хлористоводородной кислоты раствор $0,1 \mathrm{M}$ (объем среды растворения 900 мл) со скоростью 100 оборотов в минуту. В процессе определения с помощью термостата поддерживали температуру $37 \pm 2{ }^{\circ} \mathrm{C}$. Испытуемый образец (одну капсулу) помещали в сухую корзинку, которую опускали в среду растворения так, чтобы расстояние до дна сосуда было $20 \pm 2$ мм.

Через 45 мин отбирали пробу раствора, которую фильтровали через фильтр. Для каждой серии лекарственной формы рассчитывали количество фенольных соединений, перешедших в среду растворителя.

\section{Обсуждение результатов}

Описание капсул: все серии экспериментального препарата представляли собой твердые капсулы № 1, цилиндрической формы, состоящие из корпуса и крышечки желтого цвета, с гладкой поверхностью, без запаха. Содержимое капсул: порошок коричневого цвета с белыми вкраплениями с характерным запахом. 
Средняя масса капсул варьировала в пределах от 0,439 до 0,467 г, отклонение массы каждой капсулы - от 2,0 до 2,2\% и массы содержимого каждой капсулы - от 2,3 до 2,6\%, что соответствовало требованиям указанной нормативной документации (не более $10 \%$ ).

Определение подлинности капсул с экстрактом травы крапивы коноплевой проводили по фенольным соединениям методом ВЭЖХ. В ходе анализа спиртового раствора экстракта травы крапивы коноплевой обнаружено шесть соединений фенольной природы.

Идентифицированы: вещество со временем удерживания 10,3 мин - хлорогеновая кислота; 12,0 мин - шафтозид; 13,5 мин - рутин; 14,7 мин - робинин; 16,0 мин - кверцитрин; 17,4 мин - флавоноид апигениновой структуры (рис. 1, 2, табл. 1).

Количественное определение флавоноидов проводили методом спектрофотометрии в пересчете на кверцитрин, содержание которых составило 2,05 \pm 0,40\%.

Показатели «Распадаемость» и «Растворение» определяли согласно требованиям ГФ ХІІІ изд. ОФС «Распадаемость таблеток и капсул» 1.4.2.0013.15 и ОФС «Растворение для твердых дозируемых лекарственных форм» 1.4.2.0014.15. Результаты исследований приведены в таблице 2.

Рис. 1. Хроматограмма спиртового извлечения экстракта травы крапивы коноплевой

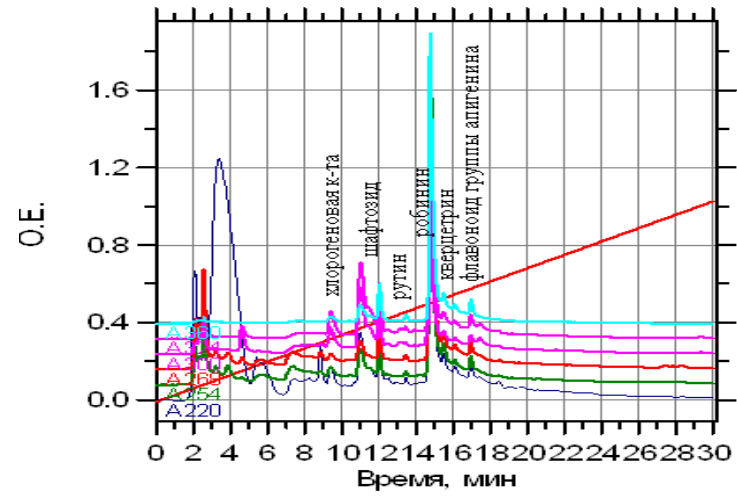

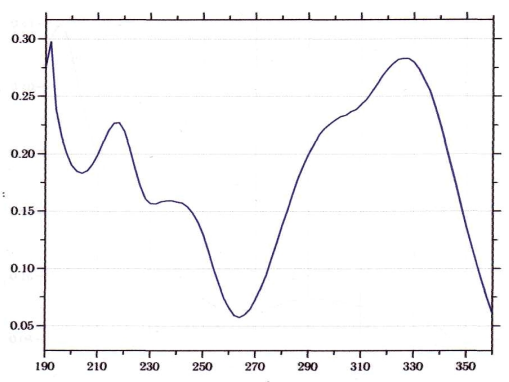

10,3 мин - хлорогеновая кислота

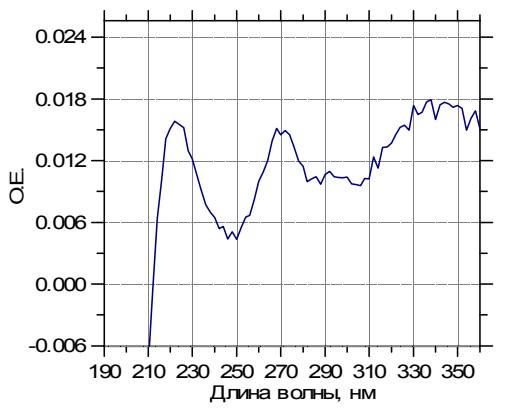

17,0 мин - кверцитрин

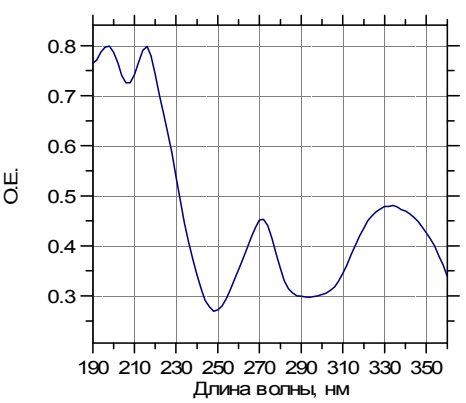

12,0 мин - шафтозид

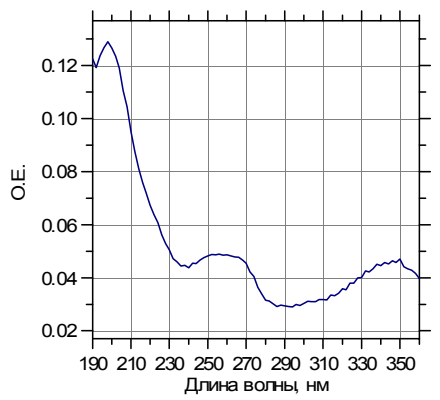

14,7 мин - робинин

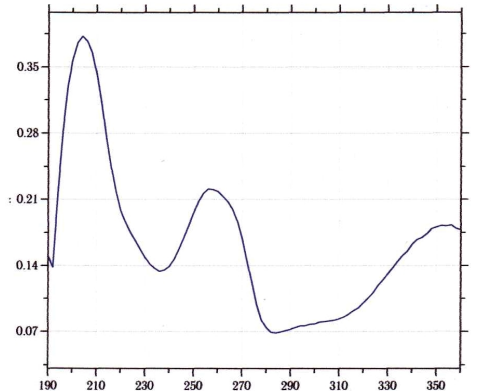

13,5 мин - рутин

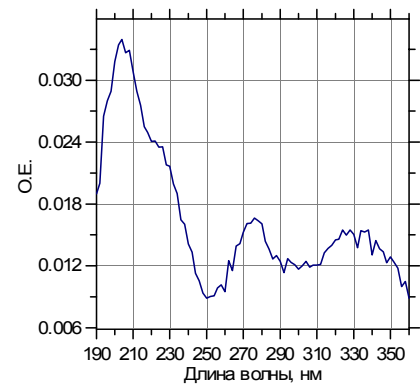

17,4 мин - флавоноид группы апигенина

Рис. 2. Спектры абсорбции стандартных образцов 
Таблица 1. Спектральные характеристики веществ, обнаруженных в спиртовом извлечении экстракта травы крапивы коноплевой

\begin{tabular}{c|c|c}
\hline Время удерживания, мин & Максимумы поглощения, нм & Идентифицированное вещество \\
\hline 10,3 & $220,240,330$ & хлорогеновая кислота \\
12,0 & $200,215,270,330$ & шафтозид \\
13,5 & $220,270,335$ & рутин \\
14,7 & $200,260,350$ & робинин \\
16,0 & $200,260,350$ & кверцитрин \\
17,4 & $220,270,330$ & флавоноид руппы апигенина \\
\hline \multicolumn{3}{|c}{} \\
\hline 10,3 & Стандартные образцы \\
12,0 & $220,240,330$ & хлорогеновая кислота \\
13,5 & $200,215,270,330$ & шафтозид \\
14,7 & $220,270,335$ & рутин \\
16,0 & $200,260,350$ & робинин \\
17,4 & $200,260,350$ & кверцитрин \\
\hline
\end{tabular}

Таблица 2. Результаты определения показателей «Распадаемость» и «Растворение» капсул «Уртикан»

\begin{tabular}{c|c|c}
\hline Номер серии & Распадаемость, мин & Растворение, $\%$ \\
\hline 1 & 2,35 & $93,14 \pm 0,13$ \\
2 & 1,83 & $90,44 \pm 1,47$ \\
3 & 2,19 & $92,17 \pm 3,54$ \\
4 & 1,90 & $90,85 \pm 0,25$ \\
5 & 2,03 & $91,31 \pm 3,23$ \\
Нормы & Не более 20 & Не менее 70 \\
\hline
\end{tabular}

На основании результатов анализа выявлено, что все серии препарата соответствуют требованиям ГФ ХІІІ изд. по показателям «Распадаемость» (не более 20 мин) и «Растворение» (от 90,44 $\pm 1,47 \%$ до $93,14 \pm 0,13 \%)-$ не менее $70 \%$.

\section{Выводы}

Таким образом, определены показатели качества капсул с экстрактом травы крапивы коноплевой сухим:

Описание - твердые капсулы № 1, цилиндрической формы, состоящие из корпуса и крышечки желтого цвета, с гладкой поверхностью, без запаха. Содержимое капсул: порошок коричневого цвета с белыми вкраплениями с характерным запахом.

Средняя масса капсул варьировала в пределах от 0,439 до 0,467 г, отклонение массы каждой капсулы - от 2,0 до 2,2\% и массы содержимого каждой капсулы - от 2,3 до 2,6\%, что соответствовало требованиям указанной нормативной документации (не более $10 \%$ ).

Идентифищированыл: хлорогеновая кислота, шафтозид, рутин, робинин, кверцитрин, флавоноид апигениновой структуры.

Количественное содержание флавоноидов в пересчете на кверцитрин составило - 2,05\%.

Фармацевтическая доступность: распадаемость капсул менее 20 мин. растворение более $70 \%$.

Полученные показатели качества использованы для разработки проекта нормативной документации «Твердые капсулы с экстрактом травы крапивы коноплевой сухим».

\section{Список литературы}

1. Кирьякова В.О. Фармакогностическое изучение некоторых видов рода Urtica, произрастающих на территории Алтайского края : дис. ... канд. фарм. наук. Барнаул, 2013. 252 с.

2. Муравьев И.А. Технология лекарств. М., 2012. Т. 2. С. 245-246.

3. Денисова М.Н. Аптечный рынок БАД // Фармация. 2007. № 6. С. 43-46.

4. Государственная фармакопея МЗ РФ. М., 2015. Т. 1. 1292 с.

5. Кирьякова В.О., Федосеева Л.М. Исследования по стандартизации экстрактов травы крапивы сухих // Сборник материалов 80-й итоговой студенческой научно-практической конференции с междунароным участием, посвященной 90-летию со дня рождения проф. Н.С. Дралюк, «Фестиваль молодежной науки-2016». Красноярск, 2016. С. 215-217.

6. Стыскин Е.Л. Практическая ВЭЖХ. М., 2006. 288 с.

7. Гринкевич Н.И. Химический анализ лекарственных растений. М., 1989. С. 90.

Поступило в редакцию 28 декабря 2016 г. 


\section{Fedoseeva L.M., Kiryakova V.O.* DEFINITION OF QUALITY INDICATORS CAPSULE DOSAGE FORM WITH AN EXTRACT OF HERB URTICAE CANNABINAE DRY}

Altai State Medical University, pr. Lenina, 40,Barnaul, 656054 (Russia), e-mail: kiryakova_viktorya@mail.ru

Conduct a comprehensive study of the aerial part of the plant genus Urtica (u. dioica, u. cannabina, u. urens), growing in the Altai Territory. Obtain dry extracts of the herbs urticae dioicae, herbs urticae cannabinae, herbs urticae urensis. In the study of the technological properties of the herb Urticae Cannabinae dry established otsyrevaemost high, so there was a need to develop a structure of a capsulated form with the addition of auxiliary substances.

Spend the standardization and evaluation of the availability of pharmaceutical capsules with an extract of herb urticae cannabinae dry. Defined quality indicators capsules: description, authenticity (identified: chlorogenic acid, shaftozid, rutin, robinin, kvertsitrin, flavonoid structure of apigenin). The quantitative content of flavonoids in terms kvertsitrin was $2,05 \pm 0,04 \%$. Established pharmaceutical availability capsules: capsules disintegration less than 20 min, more than $70 \%$ dissolution.

These quality indicators are used to develop the draft regulatory documents "hard capsules with the extract of herb Urticae Cannabinae dry."

Keywords: standardization capsules, pharmaceutical availability, extract herb Urticae Cannabinae dry.

\section{References}

1. Kiriakova V.O. Farmakognosticheskoe izuchenie nekotorykh vidov roda Urtica, proizrastaiushchikh na territorii altaiskogo kraia: diss. ... kand. farm. nauk. [Pharmacognostic study of some species of the genus Urtica, growing in the Altai Territory: diss. ... Candidate of Pharmaceutical Sciences]. Barnaul, 2013, 252 p. (in Russ.).

2. Murav'ev I.A. Tekhnologiia lekarstv. [Technology of medicines]. Moscow, 2012, vol. 2, pp. 245-246. (in Russ.).

3. Denisova, M.N. Farmatsiia, 2007, no. 6, pp. 43-46. (in Russ.).

4. Gosudarstvennaia farmakopeia $M Z R F$. [State Pharmacopoeia of the Ministry of Health of the Russian Federation]. Moscow, 2015, vol. 1, 1292 p. (in Russ.).

5. Kiriakova V.O., Fedoseeva L.M. Sbornik materialov: 80 itogovoi studencheskoi nauchno-prakticheskoi konferentsii s mezhdunaronym uchastiem, posviashchennaia 90-letiiu so dnia rozhdeniia prof. N.S. Draliuk, "Festival' molodezhnoi nauki-2016". [Collection of materials: 80 final student scientific-practical conference with international participation, dedicated to the 90th anniversary of the birth of prof. N.S. Drulyuk, "Festival of Youth Science-2016."]. Krasnoiarsk, 2016, pp. 215-217. (in Russ.).

6. Styskin E.L. Prakticheskaia VEZhKh. [Practical HPLC]. Moscow, 2006, 288 p. (in Russ.).

7. Grinkevich N.I. Khimicheskii analiz lekarstvennykh rastenii. [Chemical analysis of medicinal plants]. Moscow, 1989, p. 90. (in Russ.).

Received December 28, 2016

Revised January 18, 2017

\footnotetext{
* Corresponding author.
} 
